\title{
Correlation of Cutaneous Tension Distribution and Tissue Oxygenation with ACute External Tissue Expansion
}

\author{
C. Marquardt*, E. Bölke2*, P. A. Gerber ${ }^{3}$, G. Kukova ${ }^{3}$, M. Peiper ${ }^{4}$, E. Rusnak ${ }^{5}$, K. Orth ${ }^{6 *}$, \\ W. Fleischmann ${ }^{6 *}$ \\ ${ }^{1}$ Department of Surgery, Krankenhaus Ludwigsburg, Germany, \\ ${ }^{2}$ Department of Radiooncology, ${ }^{3}$ Department of Dermatology, ${ }^{4}$ Department of Surgery, University of Düsseldorf, Germany, \\ ${ }^{5}$ Department of Anesthesiology, State University of New York at Buffalo, USA, \\ ${ }^{6}$ Department of Orthopaedics, Krankenhaus Bietigheim-Bissingen, Germany
}

\begin{abstract}
Today, the biomechanical fundamentals of skin expansion are based on viscoelastic models of the skin. Although many studies have been conducted in vitro, analyses performed in vivo are rare. Here, we present in vivo measurements of the expansion at the skin surface as well as measurement of the corresponding intracutaneous oxygen partial pressure. In our study the average skin stretching was $24 \%$, with a standard deviation of $11 \%$, excluding age or gender dependency. The measurement of intracutaneous oxygen partial pressure produced strong inter-individual fluctuations, including initial values at the beginning of the measurement, as well as varying individual patient reactions to expansion of the skin. Taken together, we propose that even large defect wounds can be closed successfully using the mass displacement caused by expansion especially in areas where soft, voluminous tissue layers are present.
\end{abstract}

\section{BACKGROUND}

Common causes of tissue defects include trauma, surgical tissue removal or inflammation [24-27]. Defects are closed applying mobilization of the surrounding soft tissue (suture, local flap repair), tissue transplants (free flap transfer, skin transplant), or by stimulation of the body's own healing processes (granulation tissue formation, spontaneous epithelization). However, many of these methods are disadvantageous due to their technical complexicity, cosmetically and/or functionally unsatisfactory results or represent lengthy procedures.

A well-known principle allows tension at wound edges and biologically high quality wound closure through mass displacement and visco-elastic expansion (mechanical creep) in the short term and through stimulation of cell proliferation (biological creep) in the long term. Standard techniques of tissue augmentation are spherical and linear tissue expansion, by means of either subcutaneously introduced balloon catheters or balloons (internal tissue expander) or lin-

\footnotetext{
* Equal contribution
}

ear tissue expanders (external tissue expander). These techniques are gaining in importance $[1,2]$.

Within the scope of this study, an attempt was made to find a relationship between the partial pressure of oxygen in the tissue and the physical force exerted on the wound edge. The underlying hypothesis was that when certain force limits are exceeded, the force (tension) leads to deformation (expansion) of the stressed structures and in particular of the supplying blood vessels.

\section{Methods}

\section{PATIENTS}

This is a study of 10 patients who were scheduled for elective hip replacement due to coxarthrosis. The patients included 6 men and 4 women aged 35-77 years (65.4 \pm 17.4 y.; median 56 y.) with ASA scores of 1 or 2. The study was approved by the ethics committee of the University of Ulm (approval no. A 156/97). After having been informed, all patients voluntarily agreed to take part in the study.

\section{Measurements}

Measurements were taken at standard incision wounds on the thigh. Each measurement was taken following incision of the skin and subcutaneous tissue while leaving the muscle fascia intact, and following hemostasis. The patients were all under general anesthesia. The oxygen concentration in the inspiratory gaseous anesthetic $\mathrm{FiO}_{2}$ was kept constant throughout the measurement $\left(\mathrm{FiO}_{2}=0.45\right)$. Ringer lactate was administered as an infusion based on a standardized protocol. In one patient, the measurement had to be discontinued immediately at the beginning due to a dislocation of the probe. In two patients, only wound edge motion could be determined. One measurement had to be excluded due to a non-reproducible calibration of the time axis. Correspondingly, 6 analyzable measurements of the $\mathrm{pO}_{2}, 8$ analyzable measurements of wound edge motion and 7 analyzable measurements of skin expansion were included in our analyses. 


\section{Measurement of Skin Expansion}

The skin was marked over $6 \mathrm{~cm}$ perpendicular to the dorsal wound edge (Fig. 3). Markings began at the center of the wound edge and were spaced $1 \mathrm{~cm}$ apart. The site was photographed with a ruler for each weight. Expansion values were obtained by reading the distances between the markings on the projected slide delivered.

\section{Measurement of the Oxygen Partial Pressure Using A LiCOX ${ }^{\circledR}$-MEASURING PROBE}

Using a micro catheter (Catheter Micro Probe, CMP) containing a Clark polar graphic electrode, the oxygen partial pressure $\left(\mathrm{pO}_{2}\right)$ was measured in the tissue. Notably, the $\mathrm{pO}_{2}$ represents a direct measurement of the cellular oxygen supply. The micro catheter (length, $200 \mathrm{~mm}$; diameter, $0.47 \mathrm{~mm}$ ) was inserted into the subcutaneous tissue using an indwelling vein catheter.

In our experimental setup we expected initial $\mathrm{pO}_{2}$ values of approximately $50 \mathrm{mmHg}$ and, when tension was applied to the wound edge, a reduction in values toward $0 \mathrm{~mm} \mathrm{Hg}$ was anticipated. Changes of $2-3 \mathrm{~mm}$ $\mathrm{Hg}$, corresponding to $5 \%$ of the initial value, should be measurable. As any absolute measurements were not needed, the progression of the oxygen partial pressure in each patient relative to an initial value was determined, a time-consuming zero-point calibration was not necessary. However, calibration against room air was necessary to achieve accuracy of $<5 \%$.

The measurement was performed following a stabilization period of approximately 10 minutes and a calibration period of approximately 5 minutes [16]. This procedure had been confirmed in preliminary experiments. We were unable to detect a diffusion artifact in our measurements, which means that it is likely to have been substantially less than 5\%.

\section{EXPERIMENTAL SETUP}

Approximately $5 \mathrm{~mm}$ behind the dorsal wound edge of a fresh incision wound on the proximal lateral thigh, three special hook modules (total width of $45 \mathrm{~mm}, 7$ $\mathrm{mm}$ spacing between hooks) were inserted into the skin surface and threaded onto a bolt (Fig. 1). The continuous measurement of the oxygen partial pressure in the tissue was achieved by using a Licox measuring probe. Using an indwelling vein catheter, the $\mathrm{O}_{2}$-sensitive zone of the probe was positioned underneath the hook, approximately $4 \mathrm{~mm}$ under the skin

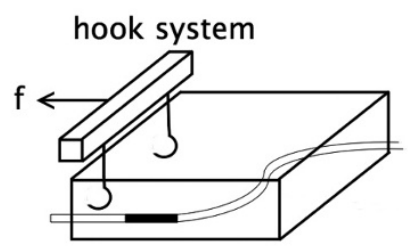

probe with sensitive zone

Fig. 1. Placement of the oxygen measuring probe in relation to the hook system $(\mathrm{f}=$ force $)$. surface (between the cutaneous and subcutaneous tissue). This corresponded to the location of maximum expected tension in the tissue.

A sterile tension cord was secured to the bolt and fed, in a direction of pull tangential to the skin surface, to a height-adjustable diversion roller installed outside the sterile operation area. The end of the tension cord could then be loaded with various weights, and the movements of the entire system of hooks, cord and weights were recorded and corresponded to the wound edge movement (Fig. 2).

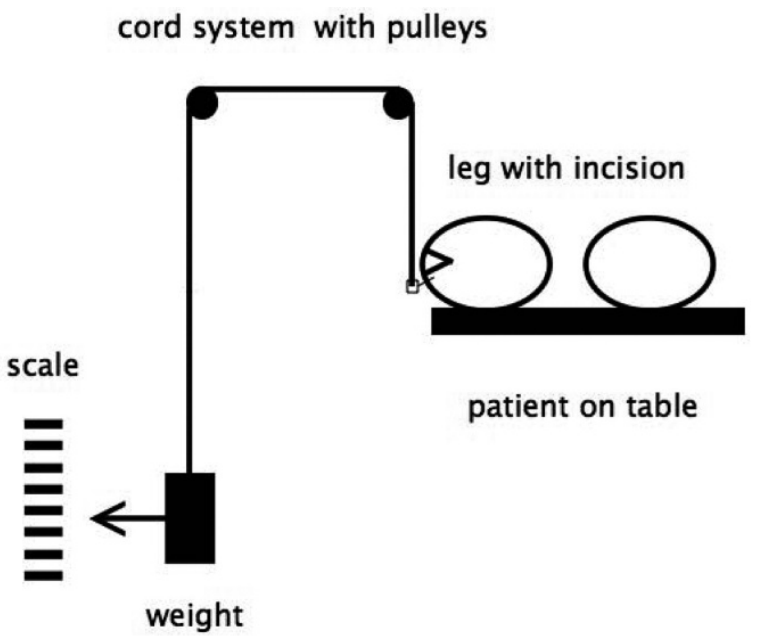

Fig. 2. Experimental setup on a patient in the operating room.

The movements of the wound edge were obtained by marking the position of the weight and taking measurements with a measuring tape. Distortions in the skin surface were analyzed on a straight line vertical to the wound edge at the center of the hook system. This was done by photographing the respective site, i.e. the marking points with attached measuring tape, at each load stage after approximately 1 minute.

\section{Calculation of Tension on the Skin with INCREMENTAL INTRODUCTION OF FORCE}

In our experiment setup (Fig. 3), the wound edge was loaded across a path of $45 \mathrm{~mm}$ with weights ranging

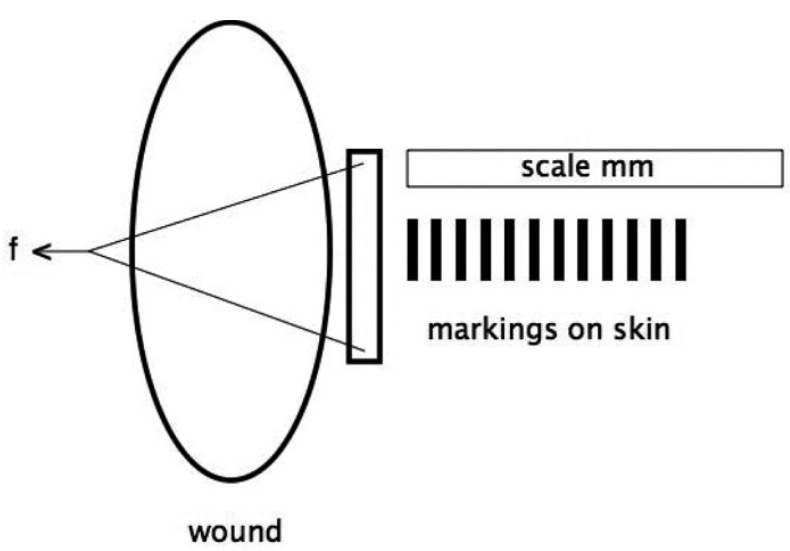

Fig. 3. Experimental setup for measurement of skin expansion. 


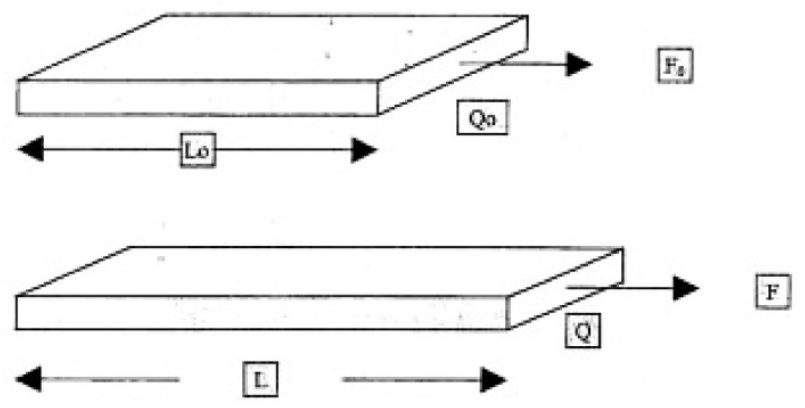

Fig.4. Tension calculation at force $F\left(F_{0}\right)$, diameter $\mathrm{Q}\left(\mathrm{Q}_{0}\right)$, length $\mathrm{L}\left(\mathrm{L}_{0}\right)$, and with initial values in parentheses.

from 0 to $3 \mathrm{~kg}$ (steps of $0.5 \mathrm{~kg} /$ measurement). The tension at the wound edge was calculated in accordance with Figure 4.

At a force of $F_{0}(F)$, a diameter of $Q_{0}(Q)$, and a length of $\mathrm{L}_{0}(\mathrm{~L})$ before expansion (after expansion), the expansion ratio is $\lambda=\mathrm{L} / \mathrm{L}_{0}$. The tension is calculated as $\sigma(F)=\frac{F}{Q} * \lambda$

\section{At $\lambda>1 \rightarrow \sigma(F)=\frac{F}{\bar{Q}_{0}}$}

If the diameter is estimated at $\mathrm{d}=4 \mathrm{~mm}$ (length of the hooks) and the thickness of the hooked skin layers, $\mathrm{b} \approx 45 \mathrm{~mm}$, the overall plane along which tension is applied $\mathrm{Q}_{0}=\mathrm{d} \times \mathrm{b}=180 \mathrm{~mm}^{2}=1.810^{-4} \mathrm{~m}^{2}$. The tension on the skin can be calculated from the force on the hook system

$\sigma(F)=F / 1.810^{-4} \mathrm{~m}^{2}$

The calculated tension values at the wound edge with the respective weights are listed in Table 1.

Table 1. Calculated tension have to be $\sigma[\mathrm{kPa}]$.

\begin{tabular}{ll}
\hline $\mathbf{m}[\mathrm{kg}]$ & $\boldsymbol{\sigma}[\mathrm{kPa}]$ \\
\hline 0.0 & 0.0 \\
0.5 & 27.8 \\
1.0 & 55.6 \\
1.5 & 83.3 \\
2.0 & 111.1 \\
2.5 & 138.9 \\
3.0 & 166.7 \\
\hline
\end{tabular}

\section{RESULTS}

The measurement of tissue or wound edge movement was accomplished by marking the position of the weight attachment and measuring the distance from the floor with a yardstick (Fig 5). In this process, the measuring error could be estimated at $\pm 5 \mathrm{~mm}$,

Mean wound expansions of 8 patients were plotted against their distance from the wound edge and against force (Fig. 6). A sigmoid curve shape representing expansion at increasing force became apparent for all distances from the wound edge. However, beginning at a distance of $40 \mathrm{~mm}$ from the wound edge, the measurement error exceeded the measured values. Furthermore, we observed a decrease in expansion with an increase in the distance from the wound edge for all forces.

In a next step, we plotted the skin expansion values against the force introduced at the wound edge (Fig. 7). The shapes of the curves representing skin expansion over force were qualitatively the same for all distances from the wound edge. Expansion values for the first $10 \mathrm{~mm}$ beyond the wound edge exceeded the remaining distances considered by a factor of 2 .

Our analyses show that the $\mathrm{pO}_{2}$ decreased with increasing force on the hooks. The decrease in the $\mathrm{pO}_{2}$ differed individually in each patient (Fig. 8). The measuring inaccuracy as indicated by the manufacturer was $1 \%$. Inter-individual fluctuations, in particular of initial values, could be eliminated by normalizing the individual measurements to their initial values. We did not observe any gender bias.

\section{Regression Data on Age Dependency}

Regression coefficients, calculated as degree of confidence $(0.42 \approx 42 \%)$, indicated no significant correlation with age. Correlations between expansion and age

Table 2. Regression data on age dependency.

\begin{tabular}{lll}
\hline $\begin{array}{l}\text { Rel. skin } \\
\text { expansion }\end{array}$ & Slope & Axis intercept \\
\hline $\mathrm{pO}_{2}(0)[\mathrm{mmHg}]$ & $\begin{array}{l}-0.0049[1 / \text { year }] \\
0.0696[\mathrm{mmHg} / \text { year }]\end{array}$ & $\begin{array}{l}30.84[\mathrm{mmHg}] \\
\end{array}$ \\
\hline
\end{tabular}

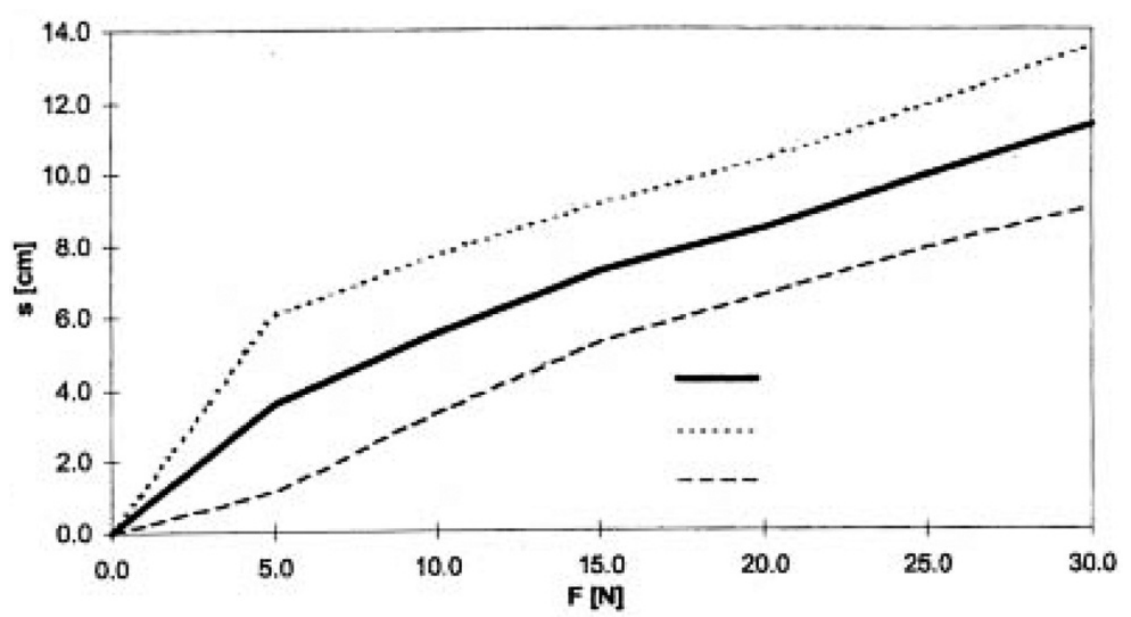

Fig. 5. Mean value (MV) and standard deviation (STD) of the wound edge movement as a factor of the force $F$ at the wound edge. 


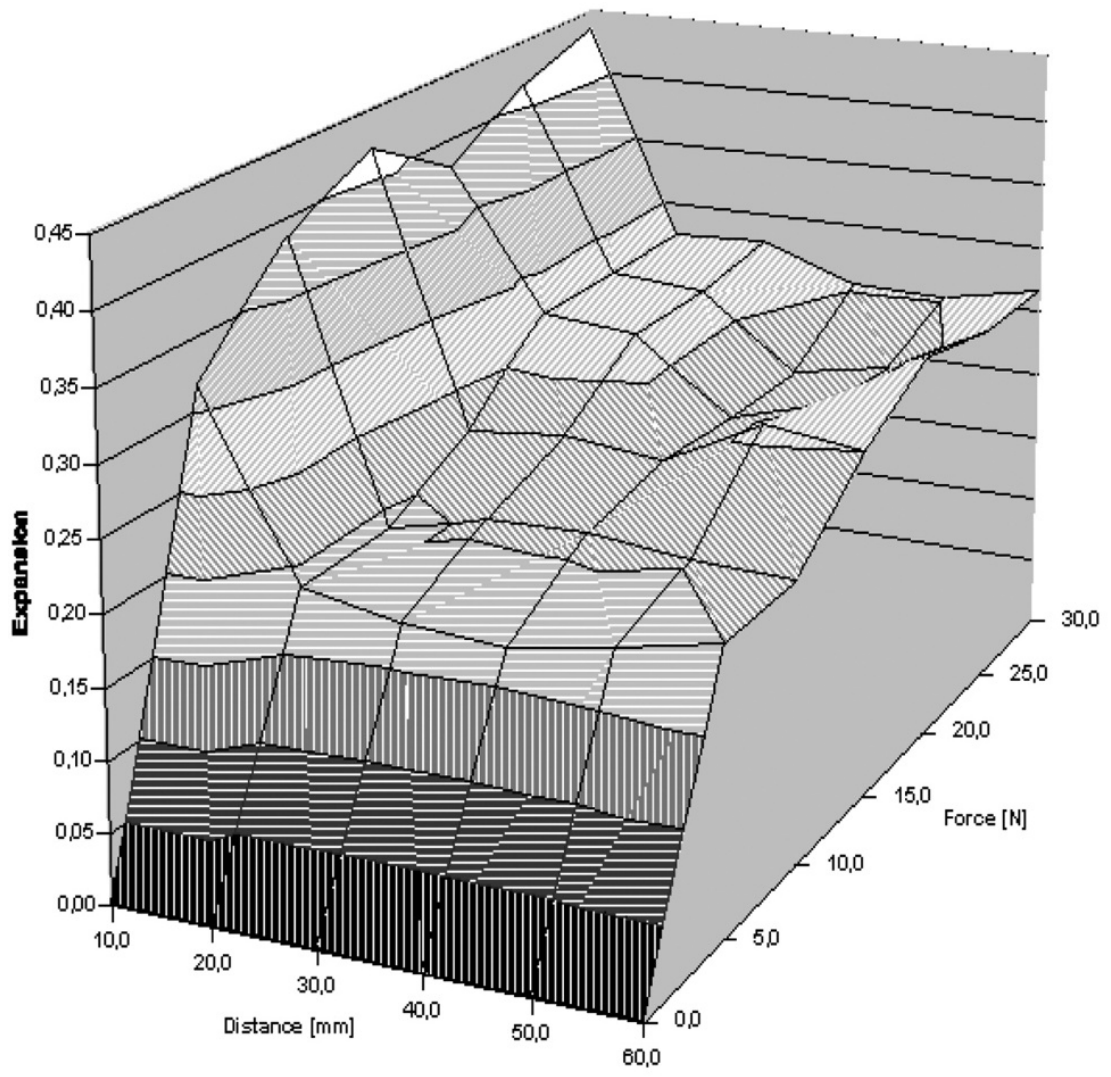

Fig. 6. Mean normalized skin expansion as a factor of the distance from the wound edge and the force $\mathrm{F}$ at the wound edge.

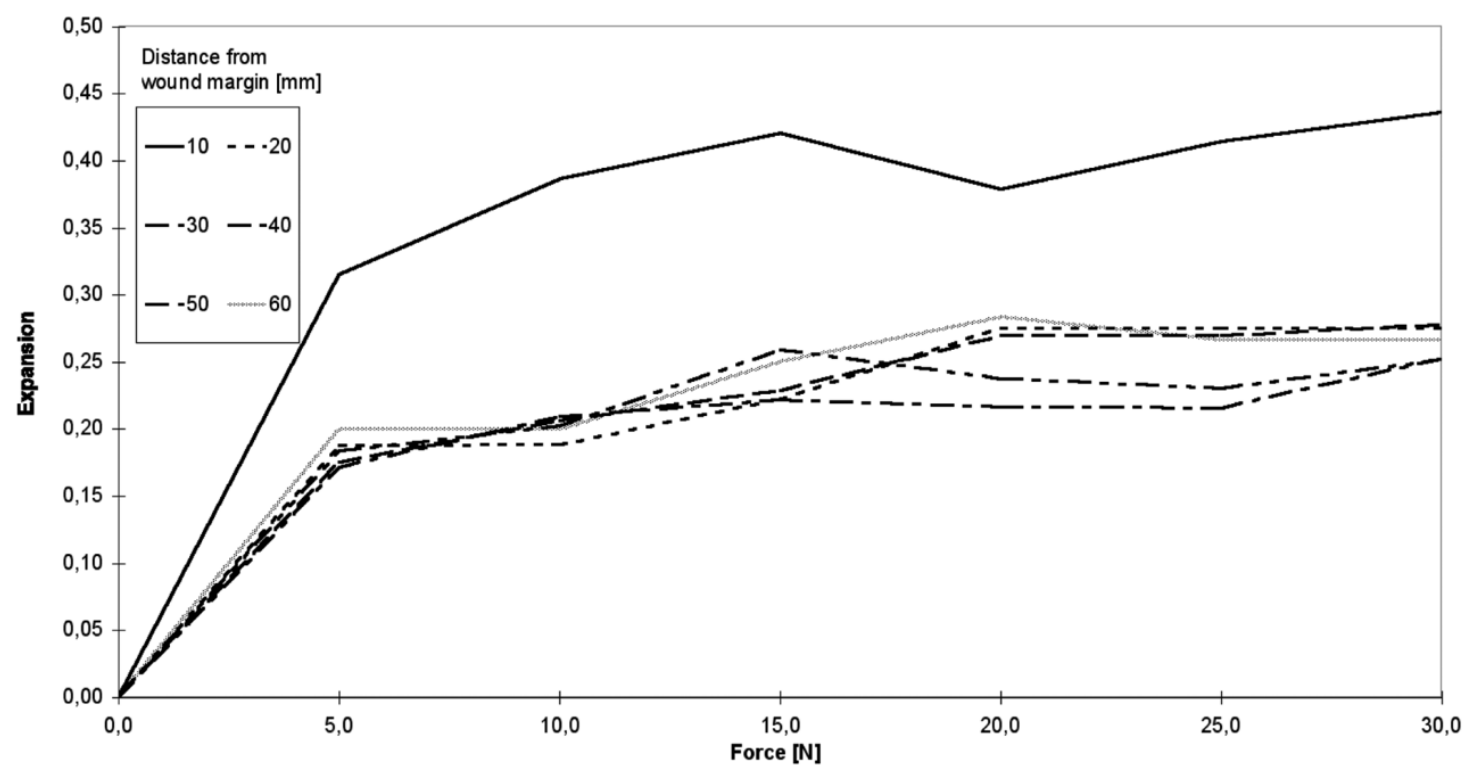

Fig. 7. Mean expansion over force F. Insert: Allocation of the individual test curves to the respective distances from the wound edge.

were weak at best. Finally, we did not observe any correlation of $\mathrm{pO}_{2}$ progression and age.

\section{Discussion}

The application of substantial forces to body tissue leads to tissue destruction as a result of either mechanical limits being exceeded or complete ischemia in the affected organ segment. The ischemia can be caused by irreversible vascular destruction, by prolonged pressure that exceeds capillary perfusion pres- sure and the ischemic tolerance of the tissue, or by protracted angiospasm. On the other hand, a "properly dosed" and, if possible, cyclically acting force in the form of tissue expansion causes stimulation of the proliferation and metabolism of the cells [3]. The problem in the use of soft tissue expansion, to bring about regenerative wound healing processes, clearly lies in the poor definition of the optimal application of force over time. Ilizarov has demonstrated that excessive or overly rapid expansion can also result in tissue degeneration [4]. Thus, the surgical maxim of 


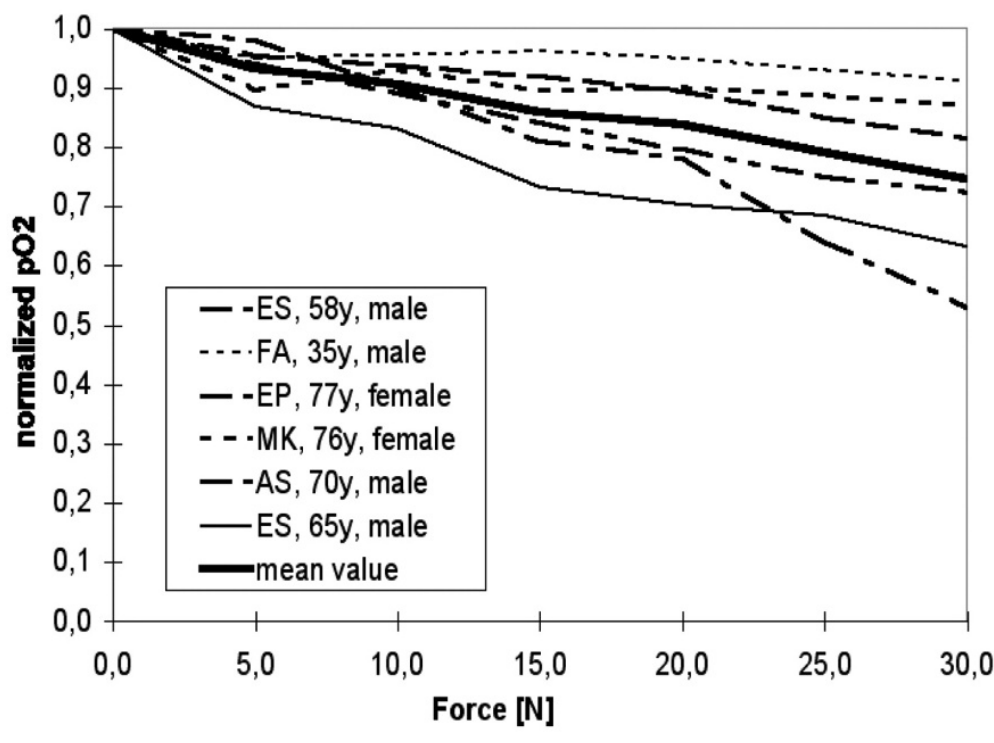

Fig. 8. Normalized oxygen partial pressure $\mathrm{pO}_{2}$ over force $\mathrm{F}$. "tension-free" wound closure cannot be accepted in this apodictic form. The correct tension is the key to optimal healing results. However, this "correct tension" must be individually defined for each cell group - a research task that has only been solved to a limited extent to date [5].

Yet, there is a theoretical risk of ischemic tissue damage caused by high, non physiological forces acting on the blood vessels. The most meaningful parameters for evaluating tissue ischemia are, in addition to oxygen saturation and blood flow, the oxygen partial pressure, as determined in this study.

The minimum oxygen partial pressure required for cell survival by oxidation of cytochrome a3 is 0.01 $\mathrm{mmHg}$ in the mitochondria. This corresponds to a $\mathrm{pO}_{2}$ of $0.05 \mathrm{mmHg}$ at the cell membrane [28]. In healthy volunteers, the intracutaneously measured $\mathrm{pO}_{2}$ was $50 \mathrm{mmHg}$ [6]. These two sets of data span a wide range. Simultaneously, the $\mathrm{pO}_{2}$ content of the tissue exerts a decisive influence on wound healing. For example, a $\mathrm{pO}_{2}$ of $20 \mathrm{mmHg}$ was measured as a limit for collagen synthesis [7]. This increased with a higher oxygen supply, which was attributed to the strong $\mathrm{pO}_{2^{-}}$ dependency of the reaction kinetics of the key enzyme for collagen synthesis (propyl-4-hydroxylase) [8]. As the ambient air already contains a $\mathrm{pO}_{2}$ of $50 \mathrm{mmHg}$, it was logical to assume a measuring range of 0 to 70 $\mathrm{mmHg}$ for testing human tissue. It is highly likely that tissue will die at a $\mathrm{pO}_{2}$ as low as $15 \mathrm{mmHg}$. This statement was confirmed by histographic measurements. Necrosis occurs at values under $10 \mathrm{mmHg}$, while tissue is not vitally threatened at values above $25 \mathrm{mmHg}$ [9].

Additional factors affecting the supply of oxygen to the tissue include the hematocrit and blood pressure, but only when their values fall below physiological limits. In contrast, the flow properties of the blood exert a strong influence on tissue supply at normal blood pressure and $\mathrm{Hb}$. Notably, it was possible to increase tissue oxygen partial pressure at normal hematocrit levels by increasing volume, e.g. by means of $\mathrm{NaCl} 0.9 \%$ infusions [10]. Accordingly, collagen synthesis was elevated in patients who received infusions of $\mathrm{NaCl}$ and glucose or dextranes [11], during wound healing. These influences of $\mathrm{Hb}$, blood pressure and volume were specified in standardized form by anesthesia in our experiment setup.

It has been shown that the $\mathrm{pO}_{2}$-measured in the subcutaneous tissue is heavily dependent on the depth of penetration and the diffusion of oxygen through the skin surface into the underlying tissue [12]. $\mathrm{A} \mathrm{pO}_{2}$ of 40-60 mmHg was expected at a tissue depth of 2-3 $\mathrm{mm}$. Notably, the diffusion component of oxygen increases as supply from the blood circulation decreases. Several studies demonstrated that this effect could be eliminated by blocking diffusion with a so-called "Oxyblock foil" [13]. When this diffusion was not blocked, a diffusion artifact of up to $5 \%$ was obtained in the tissue. When the blood supply was interrupted, the diffusion artifact exceeded $5 \%$ and the $\mathrm{pO}_{2}$ approached zero. If the measurement was taken just beneath the surface (to a depth of approximately $2 \mathrm{~mm}$ ), the $\mathrm{pO}_{2}$ did not decrease to zero, even when the blood supply was interrupted [14].

In our experiment setup, an Oxyblock ${ }^{\circledR}$ foil could not be applied, due to deformation of the tissue by the tension. This meant that diffusion of oxygen through the skin was possible, which could lead to readings of $>0 \mathrm{~mm} \mathrm{Hg}$, even with complete "no flow anoxia". However, this effect disappeared completely with increasing puncture depth of the measuring probe. Consequently, we placed the measuring probe into the intermediate zone between the cutaneous and subcutaneous tissue, which corresponds to a depth of about $4 \mathrm{~mm}$ in the skin of the thigh, so that it could be assumed that the diffusion artifact was essentially eliminated $(<1 \%)$.

Hirshowitz and coworkers reported that the normalized tension decreased to its final value of 0.95 (corresponds to $95 \%$ of the initial tension) after an average of 50 seconds and then remained constant for the next 400 seconds $[15,16]$. When measuring skin expansion in patients, it was possible to dispense with time-consuming allowances for creep behavior $(0.03 \%$ per hour [17] and hysteresis. In our test series, the skin was initially loaded with $0.5 \mathrm{~kg}$. The amount of time until readings were taken then amounted to more than 
50 seconds. All other weights were additionally attached without removing any load from the skin in the interim. Under the assumption that the creep behavior decreases exponentially, we can assume that our measurements were essentially performed in the end state. Consequently, the viscous component of the viscoelastic expansion was ignored in our analysis and the analysis was limited to the sole elastic relationship.

The skin expansions exhibited individual progressions of the test curves that were highly differentiated in quantitative terms. A correlation with the gender of the patients could not be found, nor was there any correlation with the age of patients. The slope of 0.0049 (1/year) at best suggested a decline in maximum expansion with increasing age, although the degree of confidence of $42 \%$ provided no significance. In a study by Vogel et al., significant age dependency of the elastic skin properties was reported in vitro [18]. The modulus of elasticity, maximum tension and maximum expansion increased until termination of growth and then gradually decreased with advancing age. The viscous properties, represented by relaxation, creep and hysteresis, continually decreased with advancing age.

In our study the mean expansion at the skin surface was $24 \%$. Of this expansion, 63\% (corresponding to $15 \%$ expansion) occurred after application of $5 \mathrm{~N}$ of force, while $88 \%$ (corresponding to $21 \%$ expansion) had already occurred after application of $15 \mathrm{~N}$ of force. This led to the conclusion that it is not necessary to stretch the skin to its tear limit in order to obtain sufficient tissue by utilizing viscoelasticity. In conclusion, the elastic fibers become effective in the tissue within the range of smaller expansion. This permits atraumatic expansion of the skin with small amounts of tension.

To the best of our knowledge, our study is the first to present this kind of in vivo experimental setup. The indicated movement of the wound edges represents a combination of the mobilization and displacement (viscosity) of the subdermal tissue layers with actual skin expansion. The mobilization of subdermal tissue is probably caused by elastic shear forces, which the skin exerts on the deeper tissue layers. Quantification of the individual components was not possible, as the total area of the expanded and mobilized skin was not known. In fact, a precise quantification would require an analysis of the geometrical skin conditions at the respective measurement site, which would involve recording the three-dimensional expansion profile at the surface.

With regard to $\mathrm{pO}_{2}$ measurements we observed strong inter-individual fluctuations among the initial values. An age dependency of the $\mathrm{pO}_{2}$ values could not be verified. On the anesthesia side, it could be assumed that consistent standard conditions were applied during the individual measurements on one patient. The conditions for individual patients were also standardized and therefore approximately equal. Therefore, inter-individual fluctuations due to changes in anesthesia conditions (e.g., by volume substitution or changes in the oxygen content of the inhaled anesthesia gas, $\mathrm{FiO}_{2}$ ) can be excluded.

Notably, there are various studies, demonstrating the latter also exhibited strong inter-individual fluctua- tions, as evidenced by the high standard deviation of the mean values provided (up to $20 \mathrm{~mm} \mathrm{Hg}$ ) [19, 20]. The values, measured by various authors in the subcutaneous fatty tissue of healthy volunteers, averaged 50 $\mathrm{mmHg}$ [21]. Other authors indicated values of $64 \pm$ $20 \mathrm{mmHg}$ [22]. If we compare these values with the mean value we obtained, $30.6 \pm 25.6 \mathrm{mmHg}$, which was measured while introducing tension at the wound edge, our value is significantly lower than those stated in the literature. Replacement of the measuring probes led to new initial values that were not comparable with the previously determined values [6]. This is explained by the fact that the oxygen supply is an inhomogeneous function of the location, and that it is subject to fluctuations of up to $1 \mathrm{mmHg}$ per $\mu \mathrm{m}$ of tissue, which corresponds to the functional units of a terminal arteriole with its capillaries, which supply $0.04-0.27 \mathrm{~mm}^{2}$ of skin. In our measurements, however, the fluctuations can only be attributed to a functional combination of several terminal arterioles, as the length of the measuring window of the Licox probe is $5 \mathrm{~mm}$. Finally, the average normalized $\mathrm{pO}_{2}$ decreased in linear fashion with the tension at the wound edge and still comprised $80 \%$ of its initial value at a maximum introduced force of $30 \mathrm{~N}$. This linear relationship between the $\mathrm{pO}_{2}$ and force is not consistent with the data in the literature [20,23].

In our opinion, the expansion of the skin results in deformation of the vascular tree. Its morphological structure is such that when the collagen fibers become parallelized, and therefore the elasticity and tear limit is reached, the expansion reserve of the capillaries is not yet exceeded. Only with further expansion and destruction of the collagen fibers does irreversible vascular damage does occur. Our measuring range was significantly below the range of parallelization of collagen fibers. The decrease in the $\mathrm{pO}_{2}$ within the range of lower tension is therefore best understood as a vasogenic reaction to the deformation of the capillary tree, as the experiment setup could not completely rule out vegetative influences on the tissue blood supply.

\section{Conclusions}

The average expansion of the skin on the $6 \mathrm{~cm}$ segment under consideration was $24 \pm 11 \%$. Individual patients exhibited expansion values of up to $40 \%$. Large expansion effects could also be achieved at low force levels $(15 \mathrm{~N})$ relative to the skin's resistance to tear. The intracutaneously measured tissue oxygen partial pressure $\left(\mathrm{pO}_{2}\right)$ exhibited a linear correlation with the introduced force. The very pronounced inter-individual fluctuations from initial values could not be explained. If we assume that the measured initial values are normal for each respective patient, the $\mathrm{pO}_{2}$ does not decline to less than $55 \%$ of the initial value in any patient, even at $30 \mathrm{~N}$ of introduced force. This relatively small decline suggests that the skin can be stretched even further without expecting ischemic complications. Because the values were derived from only one area of the skin, it is inadmissible to simply transfer the measured values to other regions of the body. 


\section{LITERATURE}

1. Greenbaum SS. Intraoperative tissue expansion with the Foley catheter. J Dermatol Surg Oncol. 1993; 19(12): 1079-83.

2. Frechet P. Scalp extension. J Dermatol Surg Oncol. 1993; 19(7): 616-22.

3. Ilizarov GA. The tension-stress effect on the genesis and growth of tissues. Part I. The influence of stability of fixation and soft-tissue preservation. Clin Orthop Relat Res. 1989(238): 249-81.

4. Ilizarov GA. The tension-stress effect on the genesis and growth of tissues: Part II. The influence of the rate and frequency of distraction. Clin Orthop Relat Res. 1989 (239): 263-85.

5. Vandenburgh HH. Mechanical forces and their second messengers in stimulating cell growth in vitro. Am J Physiol. 1992; 262(3 Pt 2): R350-5.

6. Weiss M, Hellner D, Schmelzle R. [Monitoring microvascular osteomyocutaneous flaps by measuring tissue oxygen pressure]. Fortschr Kiefer Gesichtschir. 1994; 39: 162-4.

7. Wu L, Mustoe TA. Effect of ischemia on growth factor enhancement of incisional wound healing. Surgery. 1995; 117(5): 570-6.

8. Hartmann M, Jonsson K, Zederfeldt B. Effect of tissue perfusion and oxygenation on accumulation of collagen in healing wounds. Randomized study in patients after major abdominal operations. Eur J Surg. 1992; 158(10): 521-6.

9. Hellner D, Schmelzle R. Laser Doppler monitoring of free microvascular flaps in maxillofacial surgery. J Craniomaxillofac Surg. 1993; 21(1): 25-9.

10. Jonsson K, et al. Tissue oxygenation, anemia, and perfusion in relation to wound healing in surgical patients. Ann Surg. 1991; 214(5): 605-13.

11. Hartmann M, Jonsson K, Zederfeldt B. Effects of dextran and crystalloids on subcutaneous oxygen tension and collagen accumulation. A randomized study in surgical patients. Eur Surg Res. 1993; 25: 270-277.

12. Evans NT, Naylor PF. The oxygen tension gradient across human epidermis. Respir Physiol. 1967; 3(1): 3842.

13. Brendler $\mathrm{T}$, et al. Influence of portocaval anastomosis (PCA) on tissue $\mathrm{PO}_{2}$ of renal cortex and skeletal muscle in rats with liver cirrhosis. Adv Exp Med Biol. 1985; 191: 703-7.

14. Strobel ES, et al. Tissue oxygen measurement and 31P magnetic resonance spectroscopy in patients with muscle tension and fibromyalgia. Rheumatol Int. 1997; 16(5): 175-80.

15. Hirshowitz B, Lindenbaum E, Har-Shai Y. A skin-stretching device for the harnessing of the viscoelastic properties of skin. Plast Reconstr Surg. 1993; 92(2): 260-70.

16. Wan Abas WA. Biaxial tension test of human skin in vivo. Biomed Mater Eng. 1994; 4(7): 473-86.

17. Larrabee WF Jr. A finite element model of skin deformation. 1. Biomechanics of skin and soft tissue: a review. Laryngoscope. 1986; 96: 399-405.
18. Vogel HG. Mechanical measurements of skin. Acta Derm Venereol Suppl Stockh. 1994; 185: 39-43.

19. Whitney JD, et al. The effects of activity and bed rest on tissue oxygen tension, perfusion, and plasma volume. Nurs Res. 1993; 42(6): 349-55.

20. Xakellis GC, et al. A comparison of changes in the transcutaneous oxygen tension and capillary blood flow in the skin with increasing compressive weights. Am J Phys Med Rehabil. 1991; 70(4): 172-7.

21. Roszinski S, Schmeller W. Differences between intracutaneous and transcutaneous skin oxygen tension in chronic venous insufficiency. J Cardiovasc Surg (Torino). 1995; 36(4): 407-13.

22. Weiss M, Hellner D, Kehding R, Schmelzle R. Oxygen pressure measurements with apolarographic needle probe in the subcutaneous fat of myocutaneous flaps. Clin Oxy Press Meas. 4: 102 -110 (1995)

23. Xakellis GC, et al. Dermal blood flow response to constant pressure in healthy older and younger subjects. J Gerontol. 1993; 48(1): M6-9.

24 Khalil PN, Siebeck M, Mutschler W, Kanz KG. The use of chicken legs for teaching wound closure skills. Eur J Med Res. 2009; 14(10): 459-60.

25 Bogner V, Keil L, Kanz KG, Kirchhoff C, Leidel BA, Mutschler W, Biberthaler P. Very early posttraumatic serum alterations are significantly associated to initial massive RBC substitution, injury severity, multiple organ failure and adverse clinical outcome in multiple injured patients. Eur J Med Res. 2009; 14(7): 284-91.

26 Witzleb WC, Stephan L, Krummenauer F, Neuke A, Günther KP. Short-term outcome after posterior versus lateral surgical approach for total hip arthroplasty - A randomized clinical trial. Eur J Med Res. 2009; 14(6): 256-63.

27 Kuehnl A, Herzog M, Schmidt M, Hornung HM, Jauch KW, Hatz RA, Graeb C. The dark side of the moon: impact of moon phases on long-term survival, mortality and morbidity of surgery for lung cancer. Eur J Med Res. 2009; 14(4): 178-81.

28. Luebbers DW. Quantitative measurement and description of oxygen supply to the tissue. In: Joebsis FF (ed) Oxygen and physiological function. Professional Information Library, Dallas 1977, 254-276.

Received: September 21, 2009 / Accepted: October 15,2009

Address for correspondence:

PD. Dr. med. Edwin Bölke

Klinik für Strahlentherapie und Radiologische Onkologie

Heinrich-Heine-Universität Düsseldorf

Moorenstraße 5

40225 Düsseldorf

Germany

Office: +49-211-8117990

Fax: +49-211-81118051

Email: boelke@med.uni-duesseldorf.de 